\title{
Das escritas escolares às escritas de si: análise de cadernos diários de alunas da Educação de Jovens e Adultos - Florianópolis - 2008
}

\section{Resumo}

O principal objetivo deste artigo é analisar dois cadernos de escrita diária de estudantes de um núcleo de Educação de Jovens e Adultos do município de Florianópolis no ano de 2008. Neste município, a EJA propõe uma metodologia de ensino baseada em projetos de pesquisa que partem do interesse e da realidade dos estudantes. Os cadernos aqui analisados são instrumentos de avaliação do curso, suportes de relatos elaborados diariamente por estudantes e respondidos por professores, que estabelecem, assim, diálogos através da escrita. Podemos, através deles, refletir sobre como esses instrumentos avaliativos deixam de ser suporte de uma escrita estritamente escolar e passam a ser suportes de uma escrita pessoal, constituinte de identidades e subjetividades, fontes privilegiadas para compreender dois dos principais campos historiográficos relacionados: a História da Cultura Escrita e a História da Educação. No âmbito da História da Cultura Escrita, grande importância se tem dado às escritas cotidianas ou "ordinárias", que começaram a ser estudadas somente a partir da última década e são fontes privilegiadas para o conhecimento do cotidiano e dos fazeres de pessoas comuns. Numa posição complementar, pode-se pensar a História da Educação também a partir dessas fontes. Neste âmbito, os cadernos expressam a vida cotidiana em salas de aula, as práticas educativas que não constam em documentos oficiais ou livros e manuais didáticos, mas que demonstram como os processos educativos são apreendidos pela ótica do estudante, dando pistas para compreender determinada cultura escolar.

Palavras-chave: Educação de Jovens e Adultos - EJA. História da Cultura Escrita. História da Educação. Cultura escolar. Cotidiano

\author{
Marilane Machado \\ Doutoranda em História da \\ Universidade Federal \\ do Paraná - UFPR. Técnica em \\ educação da Universidade do \\ Estado de Santa Catarina - \\ UDESC. \\ marilanemac@ig.com.br
}

\section{Para citar este artigo: \\ MACHADO, Marilane. Das escritas escolares às escritas de si: análise de cadernos diários de alunas da Educação de Jovens e Adultos - Florianópolis - 2008. Revista Tempo e Argumento, Florianópolis, v. 5, n.9, jan./jun. 2013. p. 86 - 101.}




\title{
From school writing to writing about onelsef: an analysis of written diaries of students from Youth and Adult Education - Florianopolis - 2008
}

\begin{abstract}
In this article the main goal is to analyze two written diaries of students from a center of Youth and Adult Education (EJA Program) in Florianopolis, Brazil, in 2008. In that city EJA Program proposes a teaching methodology based on research projects that start from students' reality and interests. The diaries analyzed in this article are instruments of course evaluation, reports prepared daily by students and answered by teachers, establishing thus dialogues through writing. By reading the diaries, one can reflect on how those evaluation tools no longer convey strictly school writing, becoming instead personal writing, constituent of identities and subjectivities, privileged sources for understanding two major historiographical related fields: History of Written Culture and History of Education. As part of History of Written Culture, great importance has been given to everyday or "ordinary" writing, which has been studied only from the last decade and is a privileged source of knowledge regarding common people's everyday life and doings. In a complementary position, History of Education can also be studied from those sources. As part of that field, diaries express everyday life in classrooms, educational practices that are not exposed in official documents or books and textbooks. Rather, they demonstrate how educational processes are perceived through the lens of students, giving clues to the understanding of a particular school culture.
\end{abstract}

Keywords: Youth and Adult Education (EJA Program). History of Written Culture. History of Education. School Culture. Everyday life. 
Cadernos escolares de tamanho pequeno $(140 \times 202 \mathrm{~mm}$ ou tamanhos aproximados), cujas capas trazem desenhos, figuras, palavras diversas... São estes suportes que guardam a escrita de estudantes frequentadores do Curso de Educação de Jovens e Adultos de diferentes localidades do município de Florianópolis. Por que nos interessam estes suportes e estas escritas? Qual sua utilidade para nós, pesquisadores?

Segundo Antonio Vinão (2008, p. 15), os cadernos escolares são fontes não menos complexas que outras, as quais, durante as últimas três décadas, figuram no cruzamento de três campos historiográficos relacionados e complementares: a história da infância, a história da cultura escrita e a história da educação. Não vou me ater aqui ao campo da história da infância, porque os cadernos em questão não foram produzidos por crianças, mas por jovens e adultos em processo de escolarização. É necessário, no entanto, compreender os cadernos como fontes importantes para o estudo da história da cultura escrita e para a história da educação.

No âmbito da história da cultura escrita, tem-se dado muita importância às escritas cotidianas ou ordinárias (VINÃO, 2008, p. 16). Neste sentido, os cadernos são importantes meios para conhecer seus autores, bem como sua rede de relações, seu modo de expressar conhecimentos, sentimentos, enfim, suas subjetividades (OLIVEIRA, 2008, p. 130).

Segundo António Castillo Gómes (2001, p. 20), a história da cultura escrita na atualidade está pautada em três conceitos-chave: os discursos, as práticas e as representações. Analisar as maneiras concretas de ler e escrever e as imagens artísticas e literárias produzidas pela sociedade acerca dos materiais escritos auxilia-nos a compreender as representações construídas por determinados indivíduos ou grupos sociais e, portanto, compreender o momento histórico em que os discursos foram elaborados.

Desta forma, o que consta dos cadernos escolares pode contribuir para entender a produção de sentidos por parte de estudantes de um determinado contexto social e as representações por eles elaboradas a partir das práticas educativas. Contribuem, enfim, para pensar a produção dessas fontes ordinárias, não somente como parte do consumo 
passivo dos conteúdos escolares, mas como parte das práticas cotidianas de consumidores que desenvolvem táticas para fugir a uma ordem estabelecida e desenvolver gostos, práticas e suas próprias artes de fazer (CERTEAU, 2008).

As pesquisadoras Ana Chrystina Venancio Mignot e Maria Teresa Santos Cunha (2006, p. 49) chamam-nos a atenção para o fato de que somente a partir da última década essa documentação, dita “ordinária”, passou a ser estudada e se aprofundou a compreensão de que ela poderia compor estudos relevantes, até então considerados pouco confiáveis, compondo temas como cultura e cotidiano escolar, imprensa pedagógica, histórias de vida de professores, professoras, alunos e alunas.

Outra utilidade dos cadernos escolares para estudos relacionados à história da cultura escrita diz respeito ao processo de aculturação e introdução nesse mundo. Estes suportes permitem compreender melhor como sujeitos históricos de determinado contexto social se apropriam das práticas da escrita, pois, como assinalou Antonio Viñao (2008, p. 16), "nos cadernos, sucessivas gerações, ou ao menos uma parte delas, assimilaram e aprenderam as pautas reguladoras do uso da escrita e, em definitivo, do espaço gráfico".

Na perspectiva da história da educação, as investigações dos cadernos escolares também são muito relevantes, continua o autor (2008, p. 16). Os historiadores da educação encontraram nesta fonte vantagens frente ao livro de texto, tendo em vista que os cadernos expressam a vida cotidiana nas salas de aula, as práticas educativas, “o que ocorre definitivamente nas salas de aula quando o professor fecha a porta”.

Algumas das possibilidades de estudo nesta perspectiva são: a história do currículo, das instituições educativas, das culturas e memórias escolares, das disciplinas, das atividades e exercícios escolares, dos ritmos e distribuição do tempo em sala de aula e como estes se aproximam ou distanciam dos tempos prescritos pela administração e programações prévias docentes ou discentes (VIÑAO, 2008, p. 17-23).

Maria Teresa Santos Cunha (2007, p. 83), ao tratar das escritas ordinárias na perspectiva da cultura escolar, destaca que os materiais produzidos por alunos são vestígios que guardam memórias da educação escolarizada; permitem rastrear o 
conjunto de códigos culturais nele inscritos e permitem ao pesquisador o reconhecimento de um sistema de regras culturalmente construídas e encarnadas nas concepções de pedagogia. Tais materiais são resultado tanto da necessidade de testemunhar o vivido, como de imposições de normas institucionais. Se conservados, podem ganhar importância para estudos na condição de escritas ordinárias:

Trata-se, portanto, da tentativa de significar e construir uma História da Educação através de uma história cultural das práticas movida pelo interesse de compreensão e conversão de objetos socialmente "insignificantes" em objetos socialmente "importantes" através de um relato histórico problematizado com uma operação historiográfica (CERTEAU, 1982) que comporta um exercício arquivístico que oferece chances para uma dada construção da realidade escolar (CHARTIER, 1994) que postula o estudo da história dos usos e das práticas do escrito escolar (CUNHA, 2007, p. 83).

Silvina Gvirtz e Marina Larrondo (2008, p. 35-37) também refletiram sobre a utilização dos cadernos como fontes "primárias" de pesquisa. Informam ser importantes fontes para a pesquisa educativa, já que os alunos os utilizam diariamente para desenvolver suas atividades. Por este motivo, permitem conservar o que foi registrado e que se vejam os efeitos da interação entre professores e alunos. Segundo as autoras, a quantidade de estudos que utilizam os cadernos escolares como fonte é bastante ampla e abarca diversas áreas, como: currículo, transmissão de ideologias e valores e estudos comparativos na perspectiva histórica e presente.

Dentro desta perspectiva, pretendo, como principal objetivo deste artigo, analisar dois cadernos de escrita diária de estudantes de um núcleo de Educação de Jovens e Adultos do município de Florianópolis no ano de 2008. Os cadernos aqui analisados são instrumentos de avaliação do curso, suportes de relatos elaborados diariamente por estudantes e respondidos por professores, que estabelecem, assim, diálogos através da escrita. É possível percebê-los como fontes de pesquisa muito ricas para a compreensão de um contexto escolar e de como é vivenciado na prática um discurso pedagógico, mas também como esses instrumentos de avaliação deixam de ser suporte de uma escrita estritamente escolar e passam a ser suportes de uma escrita pessoal, constituinte de identidades e subjetividades, fontes privilegiadas para a compreensão de dois principais 
campos historiográficos relacionados: a História da Cultura Escrita e a História da Educação.

\section{Os cadernos diários da Educação de Jovens e Adultos em Florianópolis}

Os cadernos diários que analisarei são considerados instrumentos de avaliação do curso de Educação de Jovens e Adultos da prefeitura municipal de Florianópolis, que propõe metodologias de ensino pouco convencionais para a região que compreende a capital. Neste curso, a pesquisa é o princípio educativo para as atividades pedagógicas. 0 processo de avaliação é realizado por meios diferenciados, em que não se utilizam notas para quantificar a aprendizagem, mas se segue o princípio de que, se o aluno esteve presente e participou das atividades que se propôs, algum aprendizado aconteceu.

Ao final de um ano letivo, os alunos assíduos são capazes de acumular uma carga horária total de 200 horas de curso, quantidade necessária para receber o certificado do segundo segmento do Ensino Fundamental. Os que não conseguem acumular esta carga horária têm a possibilidade de retornar no ano letivo seguinte, ou a qualquer tempo, e completar o que falta a seu pleno preenchimento, pois a carga realizada fica registrada em um banco de dados. Como toda atividade pedagógica deve ocorrer em torno de pesquisas elaboradas a partir de interesses e questionamentos dos próprios alunos, não há tempo certo para ingressar como estudante da EJA. Assim, matrículas são realizadas durante todo o ano, devido a questões burocráticas e trabalhistas, embora o curso se desenvolva no período convencional de um ano letivo.

Durante um ano, professores ${ }^{1}$ e coordenador $^{2}$ de cada núcleo de EJA em Florianópolis devem organizar o tempo escolar para a realização de três ciclos de pesquisa, quantidade necessária para que um aluno possa receber seu certificado, o que

\footnotetext{
${ }^{1}$ Para cada núcleo de EJA são contratados sete professores, um de cada disciplina obrigatória do Ensino Fundamental: português, matemática, história, geografia, ciências, artes (plásticas, cênicas ou música) e língua estrangeira (inglês ou espanhol). Na maioria dos casos, são professores contratados em caráter temporário pela prefeitura.

2 Para cada núcleo de EJA, um professor é contratado como coordenador. Geralmente são professores efetivos da rede municipal, deslocados para esta função.
} 
representa, portanto, mais um requisito. Estas pesquisas são realizadas em grupo de três alunos, que se devem reunir a partir de um interesse comum e da formulação de uma problemática de pesquisa. O processo e os resultados da pesquisa são registrados em um caderno utilizado por todos os integrantes do grupo e geralmente guardado em uma pasta, que também pertence ao grupo: o portfólio de pesquisa. Nesta pasta, os alunos guardam materiais utilizados no processo de investigação. Durante um ciclo, os alunos passam por socializações parciais de sua pesquisa, nas quais apresentam aos colegas e professores o processo que estão realizando, e uma socialização final, na qual apresentam resultados.

Ainda como forma de avaliação, cada aluno elabora um portfólio individual ao longo do curso. Geralmente, são simples envelopes personalizados, com desenhos e colagens onde são guardadas e, portanto, documentadas, as atividades ou produções individuais.

Além do portfólio individual e do portfólio de pesquisa, outro importante instrumento de avaliação é o diário individual do aluno. O Departamento de Educação Continuada da prefeitura municipal de Florianópolis assim o definiu no ano de 2008:

Cada aluno recebe um caderno com o qual manterá diálogo todos os dias com os professores e que deverá permanecer sempre no espaço educativo. Servirá para registro de suas dúvidas, suas opiniões sobre as atividades etc. Os professores deverão também fazer uso dele, principalmente para a construção de vínculo a partir de um diálogo escrito assim como colaborar com a aprendizagem, registrando transformações percebidas. O núcleo deve incentivar a socialização dos diários entre os alunos. ${ }^{3}$

Em geral, os cadernos são entregues aos alunos nas primeiras semanas do ano letivo, ou se lhes pede que tragam um caderno de casa. Cada um, então, personaliza a capa de seu caderno com imagens ou frases com as quais se identifique. Na ocasião, se Ihe explica que naquele caderno ele fará relatos diários sobre suas atividades no núcleo e os professores responderão também diariamente aos relatos, estabelecendo um diálogo através da escrita. Por ser um instrumento de avaliação do curso, a escrita neste caderno

\footnotetext{
${ }^{3}$ Estrutura, funcionamento, fundamentação e prática na Educação de Jovens e Adultos. Departamento de Educação Continuada, Secretaria Municipal de Educação de Florianópolis, 2008. Texto Mimeo.
} 
é obrigatória; também faz parte dos prerrequisitos para o término do processo de escolarização e o recebimento do certificado. Os estudantes sabem que escreverão e um dos professores lerá o que foi escrito e responderá. Esta escrita, portanto, é uma escrita vigiada, pois nela os estudantes escrevem o que consideram ser permitido dentro da relação estabelecida com seus educadores.

\section{Memórias guardadas...}

Analisarei aqui dois cadernos diários de alunas da Educação de Jovens e Adultos de Florianópolis. No ano de 2008, trabalhei como professora da EJA no núcleo do bairro Coqueiros, na Escola Municipal Almirante Carvalhal. Naquele ano, este era o único núcleo que atendia a estudantes da região continental do município de Florianópolis. Não concluí o ano letivo como professora daquele núcleo, pois, por motivos profissionais e pessoais, precisei pedir meu desligamento ao final do primeiro semestre de trabalho.

Quando pensei na possibilidade de utilizar diários individuais de alunos da EJA como fonte de pesquisa, logo me lembrei de meus alunos e alunas de 2008. Como mantenho contato com alguns deles através de uma rede social na internet, mandei uma mensagem perguntando quem ainda mantinha seus diários e se os poderia emprestar. Alguns responderam que não os haviam guardado; outros, embora os tivessem guardado, não conseguiram se encontrar comigo em razão da correria do dia-a-dia. Felizmente, porém, tive acesso a cadernos de duas alunas daquele ano, que aqui chamarei de Ka e Nana.

Estes diários são de estudantes que tiveram, por algum motivo, vontade de os guardar. São, portanto, lugares de memória, aos quais se pode recorrer para lembrar momentos que já passaram, ressignificando-os no presente. Isto nos leva a crer que esta vontade de guardar cadernos faz parte não só da construção de uma memória de sua escolarização, mas também da própria construção dessas alunas como indivíduos, produzindo uma memória de si através dos objetos que guardam. Embora estes cadernos não sejam originalmente produções espontâneas da escrita de si, de alguma forma 
ganharam, para quem os guardou, status de construção de uma identidade (GOMES, 2004).

Ao observar suas capas, podem-se perceber aspectos importantes da construção dessas identidades e subjetividades. As estudantes demonstram, por seus cadernos, gostos pessoais e preferências individuais associadas ao padrão do grupo social e do momento histórico vivido. Assim, dentro do que era de escrita obrigatória, estipulada pelo sistema de ensino no qual estavam inseridas, desenvolveram táticas ${ }^{4}$ pessoais na utilização dos cadernos.

Tendo em conta tais características, começo por analisar cada um dos cadernos. Nana escolheu um de capa dura, de fundo rosa com branco; no centro aparece o desenho de um urso segurando em uma das mãos um envelope de carta e, na outra, uma rosa corde-rosa. No topo da capa, ao centro, em tamanho menor, pode-se visualizar um desenho com três ursinhos; abaixo deles, está a frase “My Friend”. Na parte de baixo, também ao centro, há um desenho de uma caixa de presente lilás, com detalhes azuis e laço cor-derosa. Outras caixas de presentes lilás e azuis e rosas cor-de-rosa aparecem na margem esquerda e direita deste caderno.

Ka, por sua vez, utilizou dois cadernos durante o ano, devido a seus relatos serem mais detalhistas e precisarem de mais espaço. O primeiro caderno, escolhido no início do ano, traz na capa a gata Marie, personagem da Disney. A cor utilizada ao fundo da capa é o rosa-pink e, abaixo do desenho da gata, como que a apoiando, observa-se um fundo branco com desenhos de flores. Ka colou em torno do desenho diversas figuras

\footnotetext{
${ }^{4}$ Conforme Michel de Certeau (CERTEAU, 2008, p. 94), o conceito de tática pode ser definido como "a ação calculada que é determinada pela ausência de um próprio. Então nenhuma delimitação de fora Ihe fornece a condição de autonomia. A tática não tem por lugar senão o do outro. E por isso deve jogar com o terreno que lhe é imposto tal como o organiza a lei de uma força estranha. Não tem meios para se manter em si mesma, à distância, numa posição recuada, de previsão e de convocação própria: a tática é movimento "dentro do campo de visão do inimigo'[...]". Em suas pesquisas, de Certeau desenvolveu o conceito de tática para explicar como os chamados homens ordinários, supostamente entregues à passividade e à disciplina de sistemas determinados pela sociedade, através de suas práticas cotidianas reagiam silenciosamente aos sistemas e às estratégias criados por eles. Nesta pesquisa, o conceito é pertinente na medida em que pretendo analisar o uso dos cadernos escolares no cotidiano escolar da Educação de Jovens e Adultos de maneira personalizada, dando espaço às subjetividades das estudantes que os produziram e das escritas neles contidas, fugindo aos padrões preestabelecidos pelo sistema escolar, já que, mesmo um sistema como o da EJA, que propõe uma metodologia de trabalho diferenciada, possui normas a serem seguidas por estudantes e professores.
} 
autoadesivas de sapinhos, borboletas e da própria gata Marie. Seu segundo caderno, utilizado a partir do mês de agosto, traz na capa outra personagem associada ao universo infantil: a Moranguinho. A personagem aparece sentada sobre um morango gigante, ao lado de outros desenhos de morangos; atrás da personagem, aparecem bolinhas cor-derosa sobre um fundo vermelho e, no canto esquerdo, o fundo passa a ser branco, com bolinhas vermelhas. Aparecem novamente adesivos autocolantes de cachorrinhos, morangos e da própria personagem Moranguinho.

Estas capas podem demonstrar que, dentro das várias possibilidades de consumo no mercado contemporâneo, as estudantes deram preferência, por algum motivo, a estas opções, seguindo um padrão dentro de seu grupo social, faixa etária e gênero, mas ao mesmo tempo demonstrando suas individualidades.

As contracapas dos cadernos das duas estudantes parecem seguir um padrão, o que leva a concluir que receberam instruções para a escrita neste espaço. Nelas aparecem um cabeçalho com dados do núcleo de EJA onde as alunas estudaram e, abaixo, dados pessoais das próprias estudantes. Através deles, consegue-se a informação de que no ano em que frequentaram a EJA Nana havia completado 18 anos no mês de julho, enquanto Ka completara 17 no mês de novembro. Ambas pertenciam a um grupo que hoje já representa a maioria de estudantes da EJA em todo o Brasil: o de jovens que tiveram acesso e frequentaram a escola, mas não terminaram seu processo de escolarização em tempo considerado regular. ${ }^{5}$ Sobre os motivos que fizeram Nana e Ka desistirem do Ensino Fundamental no tempo considerado regular, nada foi encontrado em seus relatos. Além de terem quase a mesma idade, as duas moravam na mesma rua, que Ka identificou como pertencente ao bairro do Abraão, mas localizada na Vila Aparecida, uma das comunidades do continente, considerada periferia da cidade de Florianópolis. Estudantes dessa comunidade eram o público predominante do núcleo de Coqueiros naquele e em outros anos.

\footnotetext{
${ }^{5}$ Este fenômeno, chamado de "juvenilização da EJA", tem sido objeto de estudos acadêmicos cada vez mais recorrentes, dentre os quais podemos citar: BRUNEL, C. Jovens cada vez mais jovens na Educação de Jovens e Adultos. Porto Alegre: mediação, 2004 e CARRANO, P. C. Educação de Jovens e Adultos e Juventude: o desafio de compreender os sentidos da presença dos jovens na escola da "segunda chance”. In: REVEJ@ - Revista de Educação de Jovens e Adultos, v.1, n. o, ago. 2007. NEJA - FaE - UFMG. Belo Horizonte. Agosto de 2007.
} 
Após as informações pessoais, aparecem tópicos de orientação sobre o uso deste caderno e possibilidades de registro: 1- relatar o que desejar; 2 - escrever o que fez; 3 - o que achou das atividades e por quê? 4 - do que mais gostou e por quê? 5 - do que não gostou e por quê? 6 - o que aprendeu com seu trabalho? 7- o que aprendeu com o trabalho dos outros? 8 - dúvidas de conhecimento; 9 - dificuldades encontradas no trabalho; 10 - alguma sugestão.

Sabe-se que as duas estudantes do núcleo frequentavam diferentes salas de aula, pois, em alguns relatos de um mesmo dia, narram a realização de atividades diferentes e contato com diferentes professores; no entanto, a contracapa do caderno seguia um mesmo padrão, o que sinaliza a vontade dos professores do núcleo de nortear as orientações dadas aos alunos.

Podem-se obter muitas informações a respeito do cotidiano escolar do núcleo de Coqueiros em 2008 a partir das informações relatadas nos cadernos, assim como as impressões das estudantes sobre as atividades, entremeadas por aspectos de sua personalidade. Sabe-se, através de seus relatos, que as atividades de uma noite de estudos eram organizadas em dois momentos distintos - pois as alunas relatam diferentes atividades no "primeiro" e no "segundo" momento da noite -, intercalados por um intervalo para lanche. No relato das alunas sempre se encontram observações e recadinhos deixados pelos diferentes professores do núcleo, com pouquíssimas exceções.

Através deles, observa-se que, intercalando as atividades de pesquisa, os professores procuravam, naquele núcleo, organizar momentos de sistematização de conhecimentos de acordo com as diferentes disciplinas, mesmo que a orientação pedagógica da EJA fosse de transdisciplinaridade do conhecimento trabalhado através das pesquisas. As alunas relatam ter tido aulas com determinados professores e nomeiam essas aulas como “de matemática”, “de português”, etc., embora não estivessem distribuídas em uma grade de horários fixa como se costuma encontrar nas escolas de ensino regular. Observa-se, também, que havia momentos em que somente um professor ou professora frequentava a mesma sala de aula, enquanto, em outros momentos, dois 
ou mais professores estivessem juntos, sistematizando as atividades, prática pouco comum em escolas de Ensino Fundamental.

A noite de hoje para mim foi + ou -. Foi legal, mas não como todas as outras noites. Porque no $1^{\circ}$ momento nós tivemos Matemática com a prof $^{a} M$. Ela nos ensinou porcentagem e o que é, mas tem que prestar muita atenção para poder resolver depois a conta. (...) No $2^{\circ}$ momento veio a prof ${ }^{a} \mathrm{P}$. mas ela foi com uma acompanhante que não era a J., mas sim a profa R. de Português. A R. falou com a gente sobre resumo de texto e o que é resumo[Sic]. ${ }^{6}$

Hoje a aula foi muito bom, gostei demais. Hoje nós fizemos trabalho em grupo na aula da R. e da M. Gostei bastante, achei muito interessante! Há hoje também nós tivemos a $1^{\mathrm{a}}$ aula de inglês. Nossa foi muito legal Adorei relembrar essa aula. Nossa foi muito bom Eu espero que seja sempre assim. (...)[Sic].7

Ambos são relatos do início do ano letivo, em que as alunas estavam tendo os primeiros contatos com professores - alguns que ainda desconheciam - e com a metodologia do ensino via pesquisa intercalada com exposição de conteúdos. Observase, também, que, além dos relatos, os cadernos se tornaram um espaço em que as alunas avaliavam as aulas a que tinham assistido e expunham suas opiniões pessoais sobre conteúdos e metodologias utilizadas por professores.

A partir de outubro, quando teve início o terceiro ciclo de pesquisa, os cadernos sinalizam uma mudança na rotina e na organização do tempo escolar. Não se dividiram mais as atividades em dois momentos; embora ainda houvesse um intervalo para lanche, todo o tempo da noite era destinado à pesquisa, conforme o relato das alunas. Além disso, os diários não eram mais respondidos por todos os professores do núcleo. Em ambos os diários aparecem recados de uma única professora, a professora J., que escreve tanto para Nana quanto para Ka, o que indica que essas alunas eram orientadas em suas atividades de pesquisa por esta única professora:

E vamos com força total para o $3^{\circ}$ ciclo.

Bom, eu sei que você não tem problemas com isso, mas vou te pedir para que escreva aqui todos os dias antes do fim da aula, por isso ele sempre estará dentro da pasta de pesquisa de vocês.

Kisses, Teacher J. [Sic]. ${ }^{8}$

\footnotetext{
${ }^{6}$ Caderno de K. Relato do dia 28 de fevereiro de 2008.

${ }^{7}$ Caderno de Nana. Relato do dia 3 de março de 2008.

${ }^{8}$ Recado da professora J. no caderno de Ka. Dia 13 de outubro de 2008.
} 
Olá, minha pupila.

Início de ciclo, heim?!

Bom, quero te desejar todo sucesso para a conclusão de mais uma etapa.

E procure não faltar, ok?!

Sempre escreva no diário, tire sempre uns minutos antes do fim da aula, para isso ele estará dentro da sua pasta de pesquisa.

Kisses! :*

Teacher J. [Sic]. ${ }^{9}$

Outro aspecto interessante a respeito da organização das atividades escolares que os cadernos dessas duas alunas abordam é um certo esforço por parte de professores e da coordenação do núcleo de manter atividades complementares às de sala de aula e criar um ambiente na escola em que houvesse espaço para sociabilidades entre os alunos, para além das aulas e pesquisas. Exemplos disso são relatos de saídas para espaços externos ao ambiente escolar, ou mesmo atividades diferenciadas, de confraternização, dentro do espaço da escola. As alunas esboçam algumas impressões sobre tais atividades e aí aparecem também aspectos de seus gostos e preferências pessoais:

$\mathrm{Na}$ aula de quinta-feira pra mim foi muito legal achei a aula bem interessante. Gostei pq trabalhamos em grupo nossa a poesia que eu li é bem linda.

Depois tivemos o nosso jantar que também foi muito legal só faltou a minha vaneira hahaha. Nossa foi muito legal eu adorei devia ser assim sempre. $[\mathrm{Sic}]^{10}$

Vale ainda destacar que os diálogos entre alunas e professores registrados nos cadernos demonstram as relações estabelecidas por estes sujeitos no cotidiano escolar e as sensibilidades envolvidas neste processo, esboçados, muitas vezes, através de recadinhos direcionados especificamente a algum professor ou professora:

Obrigada pela night de hoje teachers fiquem com Deus.

OBS: J. te desejo melhoras e se cuida. Pois eu, a Ju e a Je estamos preocupadas.

Bye

$\mathrm{Ka}[\mathrm{Sic}]^{11}$

\footnotetext{
${ }^{9}$ Recado da professora J. no caderno de Nana. 13 de outubro de 2008.

10 Caderno de Nana. Relato do dia 10 de março de 2008.

${ }^{11}$ Caderno de K. Relato do dia 13 de maio de 2008. A grafia e a pontuação foram mantidas conforme foram escritas pela aluna.
} 
Por fim, eu gostaria de destacar que, além de aspectos relevantes para história da educação e para a cultura escolar, que aparecem nos relatos cotidianos presentes nos cadernos aqui analisados, estão presentes, mesmo que de maneira implícita e em número não tão expressivo, alguns aspectos sobre a vida pessoal das alunas e sua interferência no cotidiano escolar.

Hoje a aula foi legal. Estamos resumindo os textos da nossa pesquisa. Nossa confesso que esta sendo difícil mais tudo bem. J. desculpe por não estar bem hoje mais nem sempre sou uma menina agitada espuleta, as vezes tenho tristezas e não consigo me conter e acabo chorando, mas prometo que na segunda-feira vou estar bem. Ah lembre você é a melhor teacher que já tive. Beijo você mora no meu coração. [Sic]. ${ }^{12}$

\section{Considerações finais}

Através desse material, que em sua origem tinha um fim pedagógico, mas que hoje, aos olhos de um pesquisador, assume a função de fonte histórica, podemos tomar conhecimento de parte de um cotidiano e de uma cultura escolar. Compreendemos, a partir das reflexões aqui tecidas, que a cultura escolar é formada não somente pelo que as instituições educacionais e seus profissionais planejam e pretensamente executam para estudantes passivos. Os cadernos nos permitem perceber que nada é recebido passivamente, mas que esses alunos são sujeitos que carregam consigo as próprias subjetividades, que constroem sentidos a partir das situações vivenciadas, que têm gostos e preferências que interferem diretamente em suas atitudes frente à escolarização.

Desta forma, eu concluo minha reflexão acerca dos cadernos diários da Educação de Jovens e Adultos, destacando-os como fontes privilegiadas de estudo sobre o cotidiano da escolarização dos alunos no curso, mas também de suas vidas e sensibilidades pessoais. De ferramenta pedagógica e instrumento avaliativo, com os quais os professores procuravam estimular a escrita e a leitura diária de alunos da EJA e encontrar pistas sobre como melhorar sua prática pedagógica para que pudessem alcançar as expectativas e o interesse desses estudantes, os cadernos guardados

\footnotetext{
${ }^{12}$ Caderno de Nana. Relato do dia 30 de outubro de 2008. A grafia e a pontuação foram mantidas conforme foram escritas pela aluna.
} 
transformaram-se em lugares de memória e fontes ordinárias privilegiadas, demonstrando a importância que adquiriram na vida pessoal dos estudantes que os preservaram em seus arquivos pessoais.

\section{Referências}

CASTILLO GÓMES, A. (Org.). Historia de La cultura escrita. Gijón (Astúrias). Ediciones Trea. 2001.

CERTEAU, M. de. A invenção do cotidiano: 1. Artes de fazer. 14. ed. Petrópolis, RJ: Vozes, 2008.

CUNHA, M. T. S. No tom e no tema: escritas ordinárias na perspectiva da cultura escolar (segunda metade do século XX). In: BENCOSTTA, Marcus Levy Albino. (Org.). Culturas escolares, saberes e práticas educativas: itinerários históricos. São Paulo: Cortez, 2007.

GOMES, A. de C. Escrita de si, escrita da História: a título de prólogo. In: GOMES, Angela de Castro (Org.). Escrita de si, escrita da História. Rio de Janeiro: Editora FGV, 2004.

GVIRTZ, S.; LARRONDO, M. Os cadernos de classe como fonte primária de pesquisa: alcances e limites teóricos e metodológicos para sua abordagem. In: MIGNOT, Ana Chrystina Venancio (Org.). Cadernos à vista: escola, memória e cultura escrita. Rio de Janeiro: EdUERJ, 2008.

MIGNOT, A. C. V. CUNHA, M. T. S. Razões para guardar: a escrita ordinária em arquivos de professores/as. In: Revista Educação em Questão. EDUFRN. Natal | RN, v. 25, n. 11, jan./abr. 2006.

OLIVEIRA, I. B. de. Aprendendo com os cadernos escolares: sujeitos, subjetividades e práticas sociais cotidianas na escola. In: MIGNOT, Ana Chrystina Venancio (Org.). Cadernos à vista: escola, memória e cultura escrita. Rio de Janeiro: EdUERJ, 2008.

SILVA, C. B. (Org.). Histórias e trajetórias de jovens e adult@s em busca de escolarização. Florianópolis: Ed. UDESC, 2009.

VINÃO, A. Os cadernos escolares como fonte histórica: aspectos metodológicos e historiográficos. In.: MIGNOT, Ana Chrystina Venancio (Org.). Cadernos à vista: escola, memória e cultura escrita. Rio de Janeiro: EdUERJ, 2008. 
Recebido em: 16/10/2012 Aprovado em: 02/04/2013

Universidade do Estado de Santa Catarina - UDESC Programa de Pós-Graduação em História - PPGH Revista Tempo e Argumento Volume 05 - Número 09 - Ano 2013 tempoeargumento@gmail.com 